\title{
$\begin{array}{ll}\text { Research Square } & \begin{array}{l}\text { Preprints are preliminary reports that have not undergone peer review. } \\ \text { They should not be considered conclusive, used to inform clinical practice, } \\ \text { or referenced by the media as validated information. }\end{array}\end{array}$
}

\section{Age differences in associations of different indicators of socioeconomic status with social isolation: A cross-sectional study}

Lixia Ge ( $\sim$ lixia_ge@nhg.com.sg)

National Healthcare Group Health Services and Outcomes Research https://orcid.org/0000-0001-8080-7020

Bee Hoon Heng

National Healthcare Group Health Services and Outcomes Research

Woan Shin Tan

National Healthcare Group Health Services and Outcomes Research

\section{Research article}

Keywords: socioeconomic status, education, employment, income, housing type, subjective SES, social isolation, association, age difference

Posted Date: March 2nd, 2020

DOI: https://doi.org/10.21203/rs.3.rs-15624/v1

License: @ (i) This work is licensed under a Creative Commons Attribution 4.0 International License. Read Full License 


\section{Abstract}

Background Socioeconomic status is a crucial determinant of social isolation. However, little is known whether the associations between different indicators of socioeconomic status and social isolation vary across age groups. This study examined the association of individual socioeconomic status indicators with social isolation in three age groups: young (21-44 years), middle-aged (45-64 years), and older adults ( $\geq 65$ years).

Methods Cross-sectional data for 1,930 representative community-dwelling adults aged 21 and above in the Central region of Singapore was used. The 6-item Lubben Social Network Scale was used to assess social isolation. Socioeconomic status was measured using education level, employment status, personal income, housing type and self-perceived money sufficiency). Separate logistic regression analyses were conducted to examine the association between each SES indicator and social isolation in each age group.

Results Each socioeconomic indicator showed a clear gradient with social isolation and significant age disparities were found in their relationship. Socioeconomic status indicators significantly associated with social isolation were income (R2 change $=2.5 \%$ ) and selfperceived money insufficiency ( $R 2$ change $=1.5 \%$ ) in young adults, education ( $R 2$ change $=0.5 \%)$, employment status ( 2 change $=1.3 \%$ ), income ( $\mathrm{R} 2$ change $=0.8 \%$ ), housing type ( 2 change $=1.9 \%$ ) and self-perceived money insufficiency ( 2 change $=2.0 \%$ ) in middle-aged adults, and housing type ( $\mathrm{R} 2$ change $=1.3 \%$ ) and self-perceived money insufficiency (R2 change $=3.7 \%$ ) in older adults when adjusting for demographics and other indicators.

Conclusions The influence of individual socioeconomic status indicators on social isolation varied across age groups. This study provides a rationale for the choice of socioeconomic status indicator and specific interventions need to target different socioeconomic status groups for different age groups.

\section{Background}

Social isolation reflects a lack of quantity and quality of social relationships that provide positive feedback, and are meaningful to the individual [1]. Evidence suggests that people around the world are more socially isolated now than ever before [2-5]. In Singapore, population ageing and shift towards nuclear families increases the likelihood of social isolation [6]. Social isolation has increasingly recognized as a global social issue that casts significant and growing influence on people's health across life course [7], including but not limit to physical and psychological health [8-10], morbidity [11], and mortality [12, 13]. A meta-analytic review suggests that the influence of social isolation on mortality is comparable with well-established risk factors like cigarette smoking and alcohol consumption [14]. Being socially isolated also results in higher spending in health and social care services $[15,16]$. Social isolation is not only prevalent and significant for older adults, but it also affects younger individuals at different stages of life [17-19].

Socioeconomic status (SES) describes one's combined economic and social status, reflecting one's access to collectively desired resources including material goods, money, power, friendship networks, healthcare, leisure time, or educational opportunities [20]. Research has suggested that many risk factors of social isolation are unequally distributed in society and are more prevalent among economically or socially disadvantaged individuals $[1,21]$. This implies that SES plays a non-ignorable role on social isolation, whether it is direct or indirect. Education, employment status or occupational class, and income $[22,23]$ are commonly used as proxy indicators of SES.

The highest level of education is usually attained and fixed in early adulthood. It is positively associated with a range of health outcomes across all ages. Prior research reported inconsistent findings in the association between the highest level of education and social isolation. While more educated individuals could have larger confidant networks than those less well educated $[4,7]$, two other studies found that individuals with lower level of education had lower likelihood of being social isolated in mid and older life [24].

Unemployment is a stressful life event, which may affect various aspects of health [25, 26], including social isolation. Unemployment at different stages of life would have different degree of impacts on people's social life, financial status, physical and psychological health [27]. One large European study found that unemployed young and middle-aged adults were more prone to be socially isolated than their employed counterparts [28] while another study demonstrated that the retired, unemployed, sick/disabled and homemakers had poorer social engagement compared to employed older adults [29]. 
Personal or household income indicates the availability of economic and material resources. A small body of literature has documented the relationship between low-income and social isolation. A mixed method study showed that low-income individuals were more likely than their respective counterparts to feel isolated [30]. Two large scale population studies also demonstrated that low income was independently associated with social isolation $[7,24]$. The relationship between income and social isolation among different age groups was rarely documented.

Other than the above-mentioned objective measures, indicators of subjective SES are also found to be strong predictors for several aspects of health [31,32]. However, the association of self-perceived SES and social isolation is scantly explored. A study on elderly residents in Japan showed that having a low self-perceived SES was strongly associated with isolation [21]. However, whether the subjective indicator of SES is associated with social isolation in younger adults or whether it has stronger association with social isolation compared to objective indicators is still unclear.

While the associations between different indicators of SES and social isolation are extensively explored, little is known about whether and how they are differently associated at different stages of life. There is increasing awareness of the instability of an individual's SES through the life course [33], and different socioeconomic factors at different stages of the life course could have varied influence on health [34,35]. This has aroused interest in exploring how different indicators of SES affect health at different life stages [36]. As people age, their social networks may change for a variety of reasons including change in living arrangement, migration of family members or friends, change in social roles, physical illnesses, decline in physical or cognitive abilities, and death of social network members [7]. It implies that the relationship between different indicators of SES and social isolation may vary at different stages of life. Understanding the associations between specific indicators of SES and social isolation and variation in their relationship across different life stages can provide evidence on indicator selection and guide policy development or intervention design for addressing this important issue.

\section{Methods}

\section{Study aim and design}

We conducted this cross-sectional study among community-dwelling adults in Singapore to examine the relationship between individual SES measures (four objective indicators and a subjective indicator) and social isolation across three stages of adulthood: young (21-44 years), middle-aged (45-64 years), and older adults ( $\geq 65$ years).

\section{Data source and study sample}

Data were derived from the first wave of the Population Health Index (PHI) survey, which was a population-based longitudinal health survey conducted among representative community-dwelling adults in the Central Region of Singapore. Ethics approval for the PHI study was obtained from the ethical committee of the National Healthcare Group Domain Specific Review Board, Singapore (Reference Number: 2015/00269). The methodology of the PHI survey was described elsewhere [9]. A total of 1,942 adults (response rate 53.3\%) participated in the survey between November 2015 and November 2016. All participants provided written consent for participation. For the analyses, 1,930 participants (99.4\%) with valid responses on social isolation were sampled.

\section{Measures}

\section{Social isolation}

The 6-item Lubben Social Network Scale (LSNS-6), a standardized measure of social isolation, was used to screen for the presence and extent of social isolation [37]. The LSNS-6 measures the size, closeness and frequency of kinship and non-kinship contacts within an individual's social network. Three questions were asked "How many relatives do you see or hear from at least once a month?", "How many relatives do you feel close to such that you could call on them for help?" and "How many relatives do you feel at ease with that you can talk about private matters?". The word "relatives" was replaced with "friends" in these three questions to ascertain non-kinship ties. The total score of the 6 -item scale ranges from 0 to 30, with lower score indicating a greater extent of social isolation. The present study demonstrated good internal consistency of the LSNS- 6 with Cronbach's alpha $=0.82$. As suggested by Lubben [37], a score of 12 or less on the LSNS-6 indicates social isolation whereas those who scored 13 and above were considered to be not socially isolated.

\section{Socioeconomic status}




\section{Objective measures of SES}

The objective SES of the participants was measured using four indicators, including education level, employment status, personal income, and housing type.

The level of education was measured based on the highest educational attainment using the nine categories described in the Singapore Standard Educational Classification (SSEC) 2015 [38]. For this analysis, we recategorized the variable into three groups: 1: Low (primary or lower), 2: Middle (lower secondary, secondary, post-secondary), 3: High (polytechnic diploma, professional qualification, bachelor or higher).

Employment status was classified into four categories: 1: Unemployed, 2: Inactive (including homemaker, retired, and student / national service), and 3: Employed (including full-time and part-time employed, self-employed).

Personal income level was measured by the survey participants' monthly all-source income and grouped as: 1: SGD1,500 or lower, 2: SGD1,051-5,000, and 3: SGD5,001 and above (US\$1 = SGD1.38).

The type of housing in Singapore is positively correlated with household income [10,36], and is often used as a measure of SES as it broadly reflects the social positioning in the Singaporean society. More than 80 percent of Singaporean households reside in housing built by the government-owned Housing Development Board (HDB) with households in the lowest income percentiles residing in 1-and 2-room flats. More affluent households typically reside in privately built residential dwellings. In this study, we have defined three categories of housing: 1: HDB 1- and 2-room flats, 2: HDB 3- and 4-room flats, 3: HDB 5-room flats and above (including private properties).

\section{Subjective measure of SES}

We measured one's self-perceived money insufficiency (0:No, 1:Yes) based on the question "Do you often run out of money, even with proper spending plan, to buy essential items or pay bills to maintain basic living needs (i.e. accommodation, food, transportation and healthcare)?" as a subjective measure of SES.

\section{Covariates}

We also adjusted for the following covariates in the subsequent analyses: age, sex (male or female), ethnicity (Chinese, Malay, Indian, Others), marital status (single, married, divorced/widowed) and living arrangement (living alone / with unrelated individuals, living with spouse with/without child(ren), living with child(ren) but no spouse, living with parent/friend/other relative).

\section{Statistical analyses}

Descriptive analyses were first conducted for each age group with weighted mean and standard deviation (SD) reported for continuous variables, and unweighted frequency and weighted percentage reported for categorical variables. Chi-squared or Fisher's exact tests were used to determine between-group differences for categorical variables.

To examine the relationship between each SES indicator and social isolation stratified by the three age groups, we ran logistic regression analyses using each SES indicator as the independent variable and social isolation $(0=$ not isolated and $1=$ isolated $)$ as the dependent variable. To isolate the influence of each SES indicator, we have also adjusted for covariates including age, gender, ethnicity, marital status and living arrangement (Model 1). The results were presented in terms of Average Marginal Effect (AME) multiplied by 100 (AME \%). We computed the AMEs to ascertain the average change in the probability of being socially isolated as SES increases from the reference group while holding other covariates at their observed values [39]. Odds ratios (ORs) and p-values were also presented.

To study the independent association of the five SES indicators with social isolation stratified by the three age groups, we included all the five SES indicators simultaneously in the full model, adjusting for age, gender, ethnicity, marital status and living arrangement (Model 2). The AMEs were estimated for individual SES indicators.

We used McKelvey \& Zavoina's pseudo- $\mathrm{R}^{2}$ to compare estimates of explained variance from different models using the same dataset [40]. To study how each SES indicator contributed to model fit, we calculated the change in pseudo- $\mathrm{R}^{2}$ by subtracting the pseudo- $\mathrm{R}^{2}$ value of the basic model (including only social isolation as the dependent variable and the variables for adjustment) from the pseudo$\mathrm{R}^{2}$ value obtained by adding each SES indicator separately to the basic model (Model 1). In addition, for each SES indicator, we also 
calculated the absolute change in pseudo- $\mathrm{R}^{2}$ associated to the exclusion of that indicator from the full model (Model 2). All analyses were performed using Stata/SE 16.0. P $<0.05$ was set as the level of significance.

\section{Results}

\section{Characteristics of study participants}

The weighted mean age of the 1,930 participants was 48.4 years ( $S D=16.8$, range 21 - 97 years). A majority of the participants were Chinese (77.8\%), married (62.5\%), living with spouse (59.5\%), and resided in HDB 3- and 4-room flat (63.4\%). Six hundred and fiftyseven participants (43.3\%) were aged $21-44$ years old, 776 (37.9\%) were aged $45-64$ years, and $497(18.8 \%)$ were aged 65 years and above. Participants' profile stratified by age groups was presented in Table 1.

Table 1 Characteristics of study participants stratified by age groups

\begin{tabular}{|c|c|c|c|c|c|}
\hline \multirow[t]{2}{*}{ Characteristics } & \multicolumn{2}{|r|}{ All } & \multicolumn{3}{|c|}{ Age group (weighted \%) } \\
\hline & $\mathbf{N}$ & Weighted \% & $\begin{array}{l}\text { Young adults } \\
\text { (aged 21-44) (n=657) }\end{array}$ & $\begin{array}{l}\text { Middle-aged (aged 45-64) } \\
(n=776)\end{array}$ & $\begin{array}{l}\text { Older adults (aged } \geq 65) \\
(n=497)\end{array}$ \\
\hline \multicolumn{6}{|l|}{ Gender } \\
\hline Male & 852 & 48.0 & 48.4 & 49.6 & 44.0 \\
\hline Female & 1078 & 52.0 & 51.6 & 50.4 & 56.0 \\
\hline \multicolumn{6}{|l|}{ Ethnicity } \\
\hline Chinese & 1514 & 77.8 & 73.9 & 79.0 & 84.3 \\
\hline Malay & 152 & 8.1 & 8.2 & 9.1 & 5.9 \\
\hline Indian & 211 & 11.5 & 14.4 & 10.0 & 7.9 \\
\hline Others & 53 & 2.6 & 3.5 & 2.0 & 2.0 \\
\hline \multicolumn{6}{|l|}{ Marital status } \\
\hline Married & 1169 & 62.5 & 48.7 & 76.6 & 65.7 \\
\hline Single & 454 & 27.8 & 49.3 & 13.4 & 7.2 \\
\hline Divorce/widowed & 307 & 9.7 & 2.0 & 10.0 & 27.0 \\
\hline \multicolumn{6}{|l|}{ Living arrangement } \\
\hline Spouse w/wo child(ren) & 1105 & 59.5 & 46.8 & 73.1 & 61.6 \\
\hline Child(ren), no spouse & 196 & 8.1 & 2.8 & 9.0 & 18.7 \\
\hline Parent/friend/other relative & 344 & 26.1 & 47.6 & 11.3 & 6.3 \\
\hline Alone/with unrelated persons & 285 & 6.3 & 2.9 & 6.5 & 13.4 \\
\hline \multicolumn{6}{|l|}{ Education level } \\
\hline High & 441 & 27.0 & 47.4 & 15.5 & 3.1 \\
\hline Middle & 391 & 23.7 & 49.7 & 61.3 & 36.5 \\
\hline Low & 1098 & 49.4 & 2.9 & 23.2 & 60.5 \\
\hline \multicolumn{6}{|l|}{ Employment status } \\
\hline Employed & 1225 & 67.1 & 79.1 & 76.2 & 21.0 \\
\hline Inactive & 616 & 28.4 & 16.6 & 18.8 & 75.3 \\
\hline Unemployed & 89 & 4.5 & 4.3 & 5.1 & 3.7 \\
\hline \multicolumn{6}{|l|}{ Personal income } \\
\hline$>=S G D 5,001$ & 245 & 13.8 & 17.7 & 15.5 & 1.6 \\
\hline SGD1,501-SGD5,000 & 692 & 40.0 & 53.7 & 39.3 & 9.8 \\
\hline$<=S G D 1,500$ & 993 & 46.1 & 28.6 & 45.2 & 88.5 \\
\hline \multicolumn{6}{|l|}{ Housing types } \\
\hline $\mathrm{HDB}^{+}$5-room\&above & 490 & 29.5 & 29.7 & 32.1 & 23.7 \\
\hline HDB 3-\&4-room & 1260 & 63.4 & 63.8 & 61.3 & 66.6 \\
\hline HDB1-\&2-room & 180 & 7.1 & 6.4 & 6.6 & 9.7 \\
\hline \multicolumn{6}{|c|}{ Self-perceived money insufficiency } \\
\hline No & 1642 & 85.8 & 87.5 & 84.3 & 84.9 \\
\hline Yes & 288 & 14.2 & 12.5 & 15.7 & 15.1 \\
\hline
\end{tabular}

\footnotetext{
${ }^{+}$HDB referred to the Housing \& Development Board and is public housing in Singapore.
} 


\section{Association between SES indicators and social isolation in individual age groups}

We observed significant differences in the proportion of isolated individuals across the three age groups where $13.8 \%, 27.5 \%$ and $45.4 \%$ among those aged 21-44 years old, 45-64 years old and 65 years and above were socially isolated.

\section{Association between SES indicators and social isolation in young adults}

\section{Education level}

Chi-squared test showed that education level had significant association with social isolation in young adults $(p<0.001)($ Table 2$)$. Compared to those with high level of education, people with low or middle level of education had higher probability of reporting isolation given the demographic variables were held constant. Including education level in the basic model increased the model fit by $6.1 \%$, which was slightly lower compared to personal income (Table 3, Model 1). After further adjusted for other SES indicators, the contribution of education level to the model fit reduced to $1.7 \%$, and only middle education level was still significantly associated with social isolation (Table 3, Model 2).

Table 2 Proportion of isolated individuals by socioeconomic status indicators by age groups

\begin{tabular}{|c|c|c|c|c|c|c|}
\hline \multirow[t]{2}{*}{ Characteristics } & \multicolumn{2}{|c|}{$\begin{array}{l}\text { Young adults } \\
\text { (aged 21-44) } \\
(n=657)\end{array}$} & \multicolumn{2}{|c|}{ Middle-aged (aged45-64) $(n=776)$} & \multicolumn{2}{|c|}{$\begin{array}{l}\text { Older adults } \\
\text { (aged } \geq 65) \\
(n=497)\end{array}$} \\
\hline & $\mathrm{n}$ & Isolated (\%) & $\mathrm{n}$ & Isolated (\%) & $\mathrm{n}$ & Isolated (\%) \\
\hline Education level & & $p<0.001$ & & $p<0.001$ & & $p<0.001$ \\
\hline High & 480 & 8.0 & 198 & 14.7 & 26 & 37.6 \\
\hline Middle & 157 & 28.4 & 389 & 25.6 & 177 & 31.9 \\
\hline Low & 20 & 44.7 & 189 & 46.7 & 294 & 53.7 \\
\hline Employment status & & $p=0.070$ & & $p<0.001$ & & $p=0.165$ \\
\hline Employed & 534 & 13.1 & 589 & 25.7 & 102 & 42.7 \\
\hline Inactive & 97 & 11.5 & 145 & 23.8 & 374 & 45.1 \\
\hline Unemployed & 26 & 35.0 & 42 & 69.4 & 21 & 67.1 \\
\hline Personal income & & $p<0.001$ & & $p<0.001$ & & $p=0.351$ \\
\hline >=SGD 5,001 & 128 & 5.6 & 110 & 10.3 & 7 & 37.8 \\
\hline SGD1,501-SGD5,000 & 350 & 10.6 & 296 & 22.2 & 46 & 34.6 \\
\hline$<=$ SGD 1,500 & 179 & 24.7 & 370 & 38.1 & 444 & 46.7 \\
\hline Housing type & & $p<0.001$ & & $p<0.001$ & & $p<0.001$ \\
\hline $\mathrm{HDB}^{+}$5-room\&above & 171 & 6.8 & 216 & 14.4 & 103 & 35.7 \\
\hline HDB 3-\&4-room & 437 & 15.8 & 492 & 29.9 & 331 & 45.4 \\
\hline HDB1-\&2-room & 49 & 25.9 & 68 & 69.2 & 63 & 68.6 \\
\hline Self-perceived money ins & ciency & $p<0.001$ & & $p<0.001$ & & $p<0.001$ \\
\hline No & 573 & 10.6 & 649 & 22.3 & 420 & 39.7 \\
\hline Yes & 84 & 35.9 & 127 & 56.0 & 77 & 77.3 \\
\hline
\end{tabular}

${ }^{+}$HDB referred to the Housing \& Development Board and is public housing in Singapore.

$P$-values were obtained by Pearson chi-square tests or Fisher's exact tests. 
Employment status was not associated with social isolation in young adults (Table 2). With adjusting for demographic variables, unemployed young adults had an increased risk of social isolation compared to those employed (AME\%=14.43, $p=0.049$ ), but it only increased the model fit by $0.8 \%$ (Table 3, Model 1 ), which dropped to $0.2 \%$ after adjustment for other SES indicators.

\section{Personal income}

Personal income was associated with social isolation in young adults with or without adjustment for demographics or other SES indicators. Young adults with personal income of SGD5,000 or lower was associated with elevated probability of social isolation compared to those with income of SGD5,000 and above. It contributed to the model fit with higher magnitude than other SES indicators (Table 3, Model 1). With inclusion of other SES indicators in the model, personal income still contributed most to the explained variance in Model 2, and young adults with income of SGD1,500 or lower had an increased probability of isolation than those with income of SGD5,000 or above $(A M E \%=24.78)$ (Table 3, Model 2$)$.

\section{Housing type}

Including housing type in the basic model showed its significant association with social isolation (increased the model fit by $1.9 \%$ ) in young adults (Table 3, Model 1). However, after adjusted for other SES indicators, no statistical difference across three housing types was observed (Table 3, Model 2).

\section{Self-reported money insufficiency}

Young adults who reported money insufficiency for basic living needs were more likely to be isolated than those did not, even after adjusted for other SES indicators (AME\%=21.67 and 11.35, respectively) (Table 2, Model 1 \& 2). It contributed to the model fit with slightly lower magnitude compared to education level.

\section{Association between SES indicators and social isolation in middle-aged adults}

\section{Education level}

Education level had significant association with social isolation in middle-aged adults $(p<0.001)$ (Table 2$)$ and including it in the basic model increased the model fit by $5.0 \%$. Middle-aged adults with low or middle level of education had higher probability of being isolated $(A M E \%=32.11$ and 12.17, respectively) compared to those with high education level (Table 3, Model 1). The contribution of education level to the model fit reduced to $0.5 \%$ with adjustment for other SES indicators, and only middle-aged adults with low education level had higher probability of isolation (AME\%=11.34) (Table 3, Model 2).

Table 3 AME\% of reporting higher probability of isolation than the reference group and model fit stratified by age groups 


\begin{tabular}{|c|c|c|c|c|c|c|c|c|c|}
\hline \multirow[t]{2}{*}{ Socioeconomic variables } & \multicolumn{3}{|c|}{$\begin{array}{l}\text { Young adults } \\
\text { (aged 21-44) } \\
(n=657)\end{array}$} & \multicolumn{3}{|c|}{$\begin{array}{l}\text { Middle-aged } \\
\text { (aged 45-64) } \\
(n=776)\end{array}$} & \multicolumn{3}{|c|}{$\begin{array}{l}\text { Older adults } \\
(\text { aged } \geq 65) \\
(n=497)\end{array}$} \\
\hline & AME\% & OR & $p$ & AME\% & OR & $p$ & AME\% & OR & $p$ \\
\hline \multicolumn{10}{|l|}{ Education level } \\
\hline Model $1 \pm$ & \multicolumn{3}{|c|}{$R^{2}$ change $=8.0 \% *$} & \multicolumn{3}{|c|}{$R^{2}$ change $=8.4 \%$} & \multicolumn{3}{|c|}{$R^{2}$ change $=2.3 \%$} \\
\hline High & \multicolumn{3}{|l|}{ Ref } & \multicolumn{3}{|l|}{ Ref } & \multicolumn{3}{|l|}{ Ref } \\
\hline Middle & 17.83 & 3.73 & .000 & 12.17 & 2.23 & .001 & 5.27 & 1.27 & .606 \\
\hline Low & 29.40 & 6.46 & .000 & 32.11 & 5.57 & .000 & 18.82 & 2.25 & .076 \\
\hline Model $2^{++}$ & \multicolumn{3}{|c|}{$R^{2}$ change $=1.6 \% * *$} & \multicolumn{3}{|c|}{$R 2$ change $=0.6 \%$} & \multicolumn{3}{|c|}{$R^{2}$ change $=0.4 \%$} \\
\hline High & \multicolumn{3}{|l|}{ Ref } & \multicolumn{3}{|l|}{ Ref } & \multicolumn{3}{|l|}{ Ref } \\
\hline Middle & 10.29 & 2.37 & .002 & 4.49 & 1.34 & .310 & -2.66 & 0.88 & .799 \\
\hline Low & 11.10 & 2.51 & .100 & 11.34 & 1.99 & .040 & 3.97 & 1.20 & .715 \\
\hline \multicolumn{10}{|l|}{ Employment status } \\
\hline Model 1 & \multicolumn{3}{|c|}{$R^{2}$ change $=1.0 \%$} & \multicolumn{3}{|c|}{$R^{2}$ change $=3.6 \%$} & \multicolumn{3}{|c|}{$R^{2}$ change $=0.6 \%$} \\
\hline Employed & \multicolumn{3}{|c|}{ Ref } & Ref & & & Ref & & \\
\hline Inactive & 4.52 & 1.43 & .289 & -0.71 & 0.96 & .870 & -6.24 & 0.77 & .286 \\
\hline Unemployed & 14.43 & 2.59 & .049 & 36.67 & 5.11 & .000 & 5.54 & 1.26 & .611 \\
\hline Model 2 & $R^{2}$ chan & $g e=-0$ & $2 \%$ & $R^{2}$ char & $g e=1$ & & $R^{2}$ chal & $g e=0.3$ & \\
\hline Employed & Ref & & & Ref & & & Ref & & \\
\hline Inactive & -3.72 & 0.69 & .361 & -4.46 & 0.75 & .287 & -6.04 & 0.75 & .323 \\
\hline Unemployed & 1.16 & 1.11 & .854 & 21.87 & 3.17 & .003 & -5.24 & 0.78 & .628 \\
\hline Personal income & & & & & & & & & \\
\hline Model 1 & $R^{2}$ chan & $g e=11$ & $2 \%$ & $R^{2}$ char & $g e=11$ & & $R^{2}$ char & $g e=0.3$ & \\
\hline >=SGD5,001 & Ref & & & Ref & & & Ref & & \\
\hline SGD1,501-SGD5,000 & 7.69 & 2.98 & .012 & 12.59 & 3.11 & .003 & 12.24 & 1.75 & .544 \\
\hline$<=S G D 1,500$ & 24.78 & 9.51 & .000 & 32.63 & 8.60 & .000 & 16.35 & 2.08 & .401 \\
\hline Model 2 & $R^{2}$ chan & $g e=3$. & & $R^{2}$ char & $g e=1$. & & $R^{2}$ char & $g e=0$. & \\
\hline$>=S G D 5,001$ & Ref & & & Ref & & & Ref & & \\
\hline SGD1,501-SGD5,000 & 4.93 & 1.88 & .164 & 8.57 & 1.88 & .127 & 6.53 & 1.36 & .744 \\
\hline$<=$ SGD 1,500 & 18.73 & 5.41 & .001 & 16.29 & 2.96 & .017 & 5.52 & 1.30 & .777 \\
\hline Housing type & & & & & & & & & \\
\hline Model 1 & $R^{2}$ chan & $g e=3$. & & $R^{2}$ char & $g e=10$ & & $R^{2}$ chat & $g e=5 . \varepsilon$ & \\
\hline HDB 5-room\&above & Ref & & & Ref & & & Ref & & \\
\hline HDB 3-\&4-room & 7.40 & 2.08 & .023 & 14.09 & 2.42 & .000 & 10.73 & 1.61 & .052 \\
\hline HDB1-\&2-room & 17.85 & 4.06 & .003 & 51.87 & 12.46 & .000 & 38.86 & 5.57 & .000 \\
\hline Model 2 & $R^{2}$ chan & $g e=0$. & & $R^{2}$ char & $g e=2$ & & $R^{2}$ char & $g e=2.3$ & \\
\hline HDB 5-room\&above & Ref & & & Ref & & & Ref & & \\
\hline HDB 3-\&4-room & 3.34 & 1.39 & .345 & 6.83 & 1.55 & .079 & 6.34 & 1.34 & .268 \\
\hline HDB1-\&2-room & -0.76 & 0.92 & .877 & 29.42 & 4.83 & .000 & 26.65 & 3.35 & .003 \\
\hline Self-perceived money insu & ficiency & & & & & & & & \\
\hline Model 1 & $R^{2}$ chan & $g e=5$ & & $R^{2}$ char & $g e=7$ & & $R^{2}$ chal & $g e=9$. & \\
\hline No & Ref & & & Ref & & & Ref & & \\
\hline Yes & 21.67 & 3.99 & .000 & 32.70 & 4.46 & .000 & 35.80 & 5.01 & .000 \\
\hline Model 2 & $R^{2}$ chan & $g e=1$. & & $R^{2}$ char & $g e=2$ & & $R^{2}$ char & $g e=6$ & \\
\hline No & Ref & & & & & & & & \\
\hline Yes & 11.35 & 2.43 & .004 & 18.65 & 2.72 & .000 & 31.78 & 4.27 & .000 \\
\hline
\end{tabular}

Results in bold: $p<0.05$

${ }^{+}$Model 1 adjusted for age groups, gender, ethnicity, marital status and living arrangement.

${ }^{++}$Model 2 adjusted for variables in Model $1+$ other four objective SES

* McKelvey \& Zavoina's pseudo- $R^{2}$ change compared to the basic model without that specific indicator of SES

** McKelvey \& Zavoina's pseudo- $R^{2}$ change to model 2 attributed to that specific indicator of SES 
The probability of being isolated in unemployed middle-aged adults was significantly higher compared to their employed counterparts, even after adjusted for other SES indicators. Employment status contributed to the model fit by $2.5 \%$ in Model 1 and $1.3 \%$ to Model 2 , respectively (Table 3).

\section{Personal income}

The relationship between personal income and social isolation was significant in middle-aged adults, contributing to the basic model fit by $6.0 \%$. The association remained significant after adjusted for other SES indicators $\left(R^{2}\right.$ change $\left.=0.8 \%\right)$. Middle-aged adults with income of SGD1,500 or lower had higher probability of being isolated than those with income of SGD5,000 or above (AME\%=16.29) (Table 3, Model 2).

\section{Housing type}

Among middle-aged adults, a significant association between housing type and social isolation was observed. Including housing type in the basic model contributed to the model fit by $6.3 \%$, the highest among all SES indicators (Table 3, Model 1 ). The significant association remained after adjusted for other SES indicators, contributing to the model fit by $1.9 \%$ (Table 3, Model 2). Middle-aged adults residing in HDB 1- and 2-room flats had elevated probability of social isolation (AME\%=29.42) compared to those residing in HDB 5-room flats or private properties.

\section{Self-perceived money insufficiency}

Middle-aged adults who perceived money insufficiency were more likely to be socially isolated compared to those who perceived money sufficiency for basic living needs, even after adjusted for other SES indicators (AME\%=32.70 and 18.65, respectively) (Table 3, Model 1 \& 2). The inclusion of self-perceived money insufficiency improved the model fit by $5.4 \%$, slightly higher magnitude compared to education level, but lower magnitude compared to housing type and personal income. However, in the fully adjusted model, it contributed to the model fit by $2.0 \%$, which was the highest among all SES indicators (Table 3, Model 2).

\section{Association between SES indicators and social isolation in older adults}

\section{Education level}

Older adults with low level of education had higher probability of being isolated (53.7\%) compared to those with middle or high level of education (31.6\% and $37.6 \%$, respectively) (Table 2). However, the inclusion of the variable did not improve the model fit significantly. In the fully adjusted model, there was also no significant association between education level and social isolation in older adults (Table 3 , Model 2).

\section{Employment status}

Employment status and social isolation was not significantly associated in older adults (Table 2). It only contributed to the model fit by $0.3 \%$ in Model 1 and $0.1 \%$ to Model 2 (Table 3 ).

\section{Personal income}

Like employment status, the relationship between personal income and social isolation was not significant in older adults. Including it in the basic model contributed to the model fit by $0.2 \%$, lower than other SES indicators (Table 3, Model 1 ).

\section{Housing type}

Older adults residing in HDB 1- and 2-room flats were more likely to be isolated (68.6\%) compared to those residing in HDB 5-room flats or private properties (Table 2). Including housing type in the basic model contributed to the model fit by 3.3\% (Table 3, Model 1). The significant association remained after adjusted for other SES indicators, contributing to the model fit by $1.3 \%$ (Table 3, Model 2).

\section{Self-perceived money insufficiency}

Self-perceived money insufficiency was significantly associated with social isolation, even after adjusted for other SES indicators. The inclusion of this variable improved the model fit by $5.1 \%$, the highest magnitude among all SES indicators. In the fully adjusted model, it contributed to the model fit by $3.7 \%$, remained the highest out of all SES indicators (Table 3, Model 2). 


\section{Discussion}

This study examined the association of four objective SES indicators (including education level, employment status, personal income, and housing type) and one subjective SES indicator (self-perceived money insufficiency) with social isolation stratified by three age groups and the results indicated that different SES indicators were differently associated with social isolation in different age groups. We found that personal income, education level, self-perceived money insufficiency housing type, and employment status were individually associated with social isolation in young adults; each of the five SES indicators had separate association with social isolation in middle-aged adults; self-perceived money insufficiency and housing type was individually associated with social isolation in older adults. The magnitude of association between each SES indicator and social isolation varied in each age group, consistent to what reported by Geyer and colleagues [41]. The associations remained significant and varied in magnitude in each age group after fully adjusted for other SES indicators except employment status and housing type in young adults.

Educational level and personal income were associated with social isolation in young and middle-aged adults and employment status was associated with social isolation in middle-aged adults but not in adults aged 65 years and above. The results indicate that these individual-level objective SES indicators may be more suitable for young and middle-aged adults than older adults when study social isolation. Education level is related to non-material resources such as knowledge and skills, and is a strong determinant of employment and occupation as well as income [42, 43], especially during early adulthood. Unemployment presented consistent association with increased odds of social isolation in middle-aged adults where being productively employed is the norm among this life stage. The loss of daily contact with colleagues could be one mechanism. It also can be explained by self-withdrawal from families and friends due to feelings of shame and embarrassment and/or the need to cut down on expenses of socializing [44]. Low income, which financially or emotionally prevents people from participating in various social activities [45] or restrict one's capability to obtain social support, results in social isolation [46]. Unemployment, however, was not associated with isolation in young adults after adjusted for other SES indicators. This probably can be explained by the reason for unemployment as the impact of unemployment depends on the reason for unemployment $[47,48]$. For young adults, unemployment was mainly voluntary or temporary, which might have little impacts on social isolation.

Housing is an important social determinant of health [49]. Housing type, a proxy of household SES in Singapore, was found to be associated with social isolation in middle-aged and older adults in this study with those residing in HDB 1-and 2-room flats having higher probability of social isolation, even after adjusted for other SES indicators. This is consistent with a Singapore study which reported that older adults residing in HDB 3-room flat or smaller had significantly higher risk of loneliness [6]. This suggests that housing type is a sensitive SES indicator that can be used to estimate the SES effect on social isolation in middle-aged and older adults. Older adults residing in small-sized housing tend to have higher prevalence of isolation and loneliness [50]. It implies that specific interventions (i.e. a wide range of organized group activities) to be provided at small-sized housing estates should have considerable potential to tackle the isolation issue in the residents.

Similar to a recent study conducted in Japan [51], this study also showed that individuals who felt money insufficiency for daily living needs were consistently found to be strongly associated with the likelihood of being socially isolated regardless of age groups. In general, individuals' perception of their money insufficiency explained the variance in social isolation better than any of the other indicators, which indicated that the subjective SES indicator had more of an effect on social isolation than did individual objective SES indicators. This probably can be partially explained by the phenomenon that individuals who felt money insufficiency may have inferiority complex which affects their personal relationships or social interaction negatively [52].

This study contributes to the literature by investigating the most commonly used indicators of SES as well as a subjective indicator of SES in relation to probability of social isolation in three adult age groups. There are also a few limitations. First, the study used selfreported data obtained from a representative population health survey. Although the surveyors were well-trained for administering the survey questionnaire, we cannot exclude the likelihood of reporting errors. Second, we used housing type as a proxy of household SES, however, the ownership of the property or wealth was not captured. This may affect our findings as a small portion of participants were tenants or lived in HDB rental flats and staying in a rental flat was found to be associated with loneliness [6]. Third, the authors tried to disentangle each SES indicator's independent impact on social isolation by adjusting for other indicators. However, we acknowledge that the interrelationship between each SES indicator would potentially build complex pathway to social isolation and simply adjusting for other indicators might not identify one indicator's independent impact on social isolation.

\section{Conclusions}


The relationship of SES with social isolation is complex with different SES indicators having varied association with social isolation in different age groups. While subjective SES indicator had strong association with social isolation in each age group, individual-level objective SES indicators explained more variance in social isolation in young and middle-aged adults while housing type explained more variance in older adults. This implies that to tackle social isolation effectively, different strategies should be considered for people at different life stages.

\section{Abbreviations}

SES: Socioeconomic status; PHI: Population Health Index; LSNS-6: Lubben Social Network Scale; SSEC: Singapore Standard Educational Classification; HDB: Housing Development Board; AME: Average Marginal Effect

\section{Declarations}

\section{Ethics approval and consent to participate}

Ethics approval for this study was obtained from the ethical committee of the National Healthcare Group Domain Specific Review Board, Singapore (Reference Number: 2015/00269). Written informed consent was obtained from all participants of the study after being informed about the study purpose, procedure and confidentiality of the data collected.

\section{Consent for publication}

Not applicable.

\section{Availability of data and materials}

According to the Data Protection Act Commission Singapore-Advisory Guidelines for the Healthcare Sector, all the individual data collected for the Population Health Index study are protected under the Act. As such, the datasets analysed during the current study are not publicly available. However, minimal dataset underlying the findings in the manuscript is available from the corresponding author on reasonable request.

\section{Competing interests}

The authors declare that they have no competing interests.

\section{Funding}

This study did not receive any funding from any external body.

\section{Authors' contributions}

LG: conception and design, analysis of data and interpretation of results, drafting and revising, and approval of the manuscript; WST: conception and design, interpretation, critical revision and approval of the manuscript; $\mathrm{BHH}$ : conception and design, acquisition of financial support, and approval of the manuscript. All authors read and approved the final manuscript.

\section{Acknowledgements}

The authors thank Reuben Ong for administrative assistance with project management, all the trained surveyors for assistance with data collection and the subjects whose participation made this study possible.

\section{References}

Page $11 / 14$ 
1. Durcan D, Bell R. Reducing social isolation across the lifecourse. England: UCL Institute of Health Equity,Public Health England; 2015.

https://assets.publishing.service.gov.uk/government/uploads/system/uploads/attachment_data/file/461120/3a_Social_isolationFull-revised.pdf. Accessed 30 Apr 2019.

2. Lubben J, Gironda M, Sabbath E, Kong J, Johnson C. Social isolation presents a grand challenge for social work (Grand Challenges for Social Work Initiative Working Paper No. 7). Working Paper. Cleveland, OH: American Academy of Social Work and Social Welfare; 2015. http://grandchallengesforsocialwork.org/wp-content/uploads/2015/12/WP7-with-cover.pdf. Accessed 7 Oct 2019.

3. Ibrahim R, Momtaz YA, Hamid TA. Social isolation in older Malaysians: prevalence and risk factors. Psychogeriatrics. 2013;13:719.

4. McPherson M, Smith-Lovin L, Brashears ME. Social isolation in America: changes in core discussion networks over two decades. 2006;71:353-75.

5. Holt-Lunstad J. The potential public health relevance of social isolation and loneliness: prevalence, epidemiology, and risk factors. Public Policy Aging Rep. 2017;27:127-30.

6. Wee LE, Tsang TYY, Yi H, Toh SA, Lee GL, Yee J, et al. Loneliness amongst low-socioeconomic status elderly Singaporeans and its association with perceptions of the neighbourhood environment. Int J Environ Res Public Health. 2019;16. doi:10.3390/ijerph16060967.

7. Cudjoe TKM, Roth DL, Szanton SL, Wolff JL, Boyd CM, Thorpe RJ. The epidemiology of social isolation: National Health and Aging Trends Study. J Gerontol B Psychol Sci Soc Sci. 2018;:gby037.

8. Cacioppo JT, Cacioppo S. Older adults reporting social isolation or loneliness show poorer cognitive function 4 years later. Evid Based Nurs. 2014;17:59-60.

9. Ge L, Yap CW, Ong R, Heng BH. Social isolation, loneliness and their relationships with depressive symptoms: A population-based study. PLOS ONE. 2017;12:e0182145.

10. Ng CW, Tan WS, Gunapal PP, Wong LY, Heng BH. Association of Socioeconomic Status (SES) and Social Support with Depressive Symptoms among the Elderly in Singapore. Ann Acad Med Singapore. 2014;43:576-87.

11. Bhatti AB, Haq A ul. The pathophysiology of perceived social isolation: effects on health and mortality. Cureus. 2017;9. doi:10.7759/cureus.994.

12. Holt-Lunstad J, Smith TB, Baker M, Harris T, Stephenson D. Loneliness and social isolation as risk factors for mortality: a metaanalytic review. Perspect Psychol Sci. 2015;10:227-37.

13. Laugesen K, Baggesen LM, Schmidt SAJ, Glymour MM, Lasgaard M, Milstein A, et al. Social isolation and all-cause mortality: a population-based cohort study in Denmark. Scientific Reports. 2018;8:4731.

14. Holt-Lunstad J, Smith TB, Layton JB. Social relationships and mortality risk: a meta-analytic review. PLOS Medicine. 2010;7:e1000316.

15. Saito M, Aida J, Kondo N, Saito J, Kato H, Ota Y, et al. Reduced long-term care cost by social participation among older Japanese adults: a prospective follow-up study in JAGES. BMJ Open. 2019;9:e024439.

16. Shaw JG, Farid M, Noel-Miller C, Joseph N, Houser A, Asch SM, et al. Social isolation and medicare spending: among older adults, objective social isolation increases expenditures while loneliness does not. J Aging Health. 2017;29:1119-43.

17. Child ST, Lawton L. Loneliness and social isolation among young and late middle-age adults: associations with personal networks and social participation. Aging \& Mental Health. 2019;23:196-204.

18. Matthews T, Danese A, Wertz J, Odgers CL, Ambler A, Moffitt TE, et al. Social isolation, loneliness and depression in young adulthood: a behavioural genetic analysis. Soc Psychiatry Psychiatr Epidemiol. 2016;51:339-48.

19. Primack BA, Shensa A, Sidani JE, Whaite EO, Lin LY, Rosen D, et al. Social media use and perceived social isolation among young adults in the U.S. Am J Prev Med. 2017;53:1-8.

20. Oakes JM, Rossi PH. The measurement of SES in health research: current practice and steps toward a new approach. Social Science \& Medicine. 2003;56:769-84.

21. Gouda K, Okamoto R. Current status of and factors associated with social isolation in the elderly living in a rapidly aging housing estate community. Environ Health Prev Med. 2012;17:500-11.

22. Doshi T, Smalls BL, Williams JS, Wolfman TE, Egede LE. Objective and subjective measures of socioeconomic status and cardiovascular risk control in adults with diabetes. Am J Med Sci. 2016;352:36-44.

Page 12/14 
23. Sumanen H, Pietiläinen O, Lahti J, Lahelma E, Rahkonen O. Interrelationships between education, occupational class and income as determinants of sickness absence among young employees in 2002-2007 and 2008-2013. BMC Public Health. 2015;15. doi:10.1186/s12889-015-1718-1.

24. Menec VH, Newall NE, Mackenzie CS, Shooshtari S, Nowicki S. Examining individual and geographic factors associated with social isolation and loneliness using Canadian Longitudinal Study on Aging (CLSA) data. PLoS One. 2019;14. doi:10.1371/journal.pone.0211143.

25. McKee-Ryan F, Song Z, Wanberg CR, Kinicki AJ. Psychological and physical well-being during unemployment: a meta-analytic study. J Appl Psychol. 2005;90:53-76.

26. Norström F, Virtanen P, Hammarström A, Gustafsson PE, Janlert U. How does unemployment affect self-assessed health? A systematic review focusing on subgroup effects. BMC Public Health. 2014;14:1310.

27. Brydsten A, Hammarström A, San Sebastian M. Health inequalities between employed and unemployed in northern Sweden: a decomposition analysis of social determinants for mental health. Int J Equity Health. 2018;17:59.

28. Dieckhoff M, Gash V. Unemployed and alone? Unemployment and social participation in Europe. International Journal of Sociology and Social Policy. 2015;35:67-90.

29. Whitley E, Popham F. Leaving the labour market later in life: how does it impact on mechanisms for health? Occup Environ Med. 2017;74:877-86.

30. Stewart MJ, Makwarimba E, Reutter LI, Veenstra G, Raphael D, Love R. Poverty, sense of belonging and experiences of social isolation. Journal of Poverty. 2009;13:173-95.

31. Nobles J, Ritterman Weintraub M, Adler N. Subjective socioeconomic status and health: relationships reconsidered. Soc Sci Med. 2013;82:58-66.

32. Singh-Manoux A, Marmot MG, Adler NE. Does subjective social status predict health and change in health status better than objective status? Psychosom Med. 2005;67:855-61.

33. Braveman PA, Cubbin C, Egerter S, Chideya S, Marchi KS, Metzler M, et al. Socioeconomic status in health research: one size does not fit all. JAMA. 2005;294:2879-88.

34. Heslop P, Davey Smith G, Macleod J, Hart C. The socioeconomic position of employed women, risk factors and mortality. Social Science \& Medicine. 2001;53:477-85.

35. Smith GD, Hart C, Blane D, Gillis C, Hawthorne V. Lifetime socioeconomic position and mortality: prospective observational study. BMJ. 1997;314:547-52.

36. Malhotra R, Malhotra C, Chan A, Østbye T. Life-course socioeconomic status and obesity among older Singaporean Chinese men and women. J Gerontol B Psychol Sci Soc Sci. 2013;68:117-27.

37. Lubben J, Blozik E, Gillmann G, Iliffe S, von Renteln Kruse W, Beck JC, et al. Performance of an abbreviated version of the Lubben Social Network Scale among three European community-dwelling older adult populations. Gerontologist. 2006;46:503-13.

38. DOS D of S. Singapore Standard Educational Classification 2015. Singapore; 2015. https://www.singstat.gov.sg/-/media/files/standards_and_classifications/educational_classification/ssec2015-report.pdf. Accessed 16 May 2019.

39. Torrres-Reyna O. Predicted probabilities and marginal effects after (ordered) logit/probit using margins in Stata. New Jersey: Princeton University; 2014.

40. DeMaris A. Explained variance in logistic regression: A Monte Carlo study of proposed measures. Sociological Methods \& Research. 2002;31:27-74.

41. Geyer S, Hemstrom O, Peter R, Vagero D. Education, income, and occupational class cannot be used interchangeably in social epidemiology. Empirical evidence against a common practice. J Epidemiol Community Health. 2006;60:804-10.

42. Galobardes B, Shaw M, Lawlor DA, Lynch JW, Davey Smith G. Indicators of socioeconomic position (part 2). J Epidemiol Community Health. 2006;60:95-101.

43. Piha K, Laaksonen M, Martikainen P, Rahkonen O, Lahelma E. Interrelationships between education, occupational class, income and sickness absence. Eur J Public Health. 2010;20:276-80.

44. Mann JL. Some thoughts for the unemployed on avoiding the trap of social isolation. Psychology Today. 2012. https://www.psychologytoday.com/int//blog/jobless-not-joyless/201208/some-thoughts-the-unemployed-avoiding-the-trap-socialisolation. 
45. Joo YM, Ng LK, Chua HC, Xiong HM, Mohammed M. Strengthening communities with low-income families in Singapore. Singapore: Lee Kuan Yew School of Public Policy, National University of Singapore; 2017. https://lkyspp.nus.edu.sg/docs/defaultsource/admissions/mpp/pae-final-report-strengthening-communities-with-low-income-families.pdf?sfvrsn=713970b_2. Accessed 10 May 2019.

46. Dodge KA, Pettit GS, Bates JE. Socialization mediators of the relation between socioeconomic status and child conduct problems. Child Dev. 1994;65 2 Spec No:649-65.

47. Chadi A. How to distinguish voluntary from involuntary unemployment: on the relationship between the willingness to work and unemployment-induced unhappiness. Kyklos. 2010;63:317-29.

48. Mosca I, Barrett A. The impact of voluntary and involuntary retirement on mental health: evidence from older Irish adults. J Ment Health Policy Econ. 2016;19:33-44.

49. Krieger J, Higgins DL. Housing and health: time again for public health action. Am J Public Health. 2002;92:758-68.

50. Gray A, Worlledge G. Addressing loneliness and isolation in retirement housing. Ageing \& Society. 2018;38:615-44.

51. Ejiri M, Kawai H, Fujiwara Y, Ihara K, Hirano H, Kojima M, et al. Predictors of social isolation among older people living in urban area: a prospective study. Nihon Koshu Eisei Zasshi. 2018;65:125-33.

52. Donaldson J, Balakrishan B, Smith CJ, Mumtaz Md Kadir, Sanushka Mudaliar, Singapore Management University, et al. Elderly population in Singapore: understanding social, physical and financial needs. 2015. 